Vol. 17 (2008): 3-17.

\title{
The effect of single farm payments on less favoured areas agriculture in Scotland: a CGE analysis
}

\author{
Ayele Gelan \\ The Macaulay Institute, Craigiebuckler, Aberdeen AB15 8QH, United Kingdom, \\ present address: International Livestock Research Institute (ILRI), PO Box 30709 \\ Nairobi00100,Kenya,email:A.Gelan@cgiar.org \\ Gerald Schwarz \\ The Macaulay Institute, Craigiebuckler, Aberdeen AB15 8QH, United Kingdom, \\ e-mail: g.schwarz@macaulay.ac.uk
}

\begin{abstract}
This study quantifies impacts of common agricultural policy reform on farming in Less Favoured Areas (LFAs) in Scotland. LFAs are characterised by low agricultural productivity, because of unfavourable natural conditions, which allow only extensive farming systems such as cattle and sheep rearing. The differential impacts of the single farm payment on LFA farming is examined using a CGE modeling framework that accounts for inter-sectoral linkage effects. The simulation results indicate that the policy reform has considerably larger adverse effects on LFA farms than non-LFA farms and emphasize the need to consider spatially differential impacts in further adjustments to policy reforms taking into account local circumstances.
\end{abstract}

Key-words: Common Agricultural Policy Reform, single farm payments, decoupling, Less Favoured Areas, Scotland.

\section{Introduction}

Less Favoured Areas (LFAs) account for 85 percent of the Scottish land area and comprise of some of the most marginal land areas in the EU. LFAs are characterised by biophysical conditions such as poor rocky soils and heather moorlands, particularly in the Highlands and Islands of Scotland, unfavourable for agricultural production; and accelerated outmigration and low population density with livelihood predominantly dependent on agricultural activity. These natural and socio-economic conditions in LFAs allow only extensive agricultural produc- 


\section{AGRICULTURAL AND FOOD SCIENCE}

\section{Gelan, A. \& Schwarz, G. Impacts of decoupling on agriculture in Scottish less favoured areas}

tion systems such as cattle and sheep grazing and livestock rearing systems which have lower than average productivity compared to the main indices of economic performance in agriculture (SEERAD 2003). Consequently, unfavourable natural and socio-economic conditions resulted in low productivity, limited alternatives for agricultural activities and hence high dependency on subsidies.

The recent CAP reform implemented in 2005 brought key changes to the subsidy system for Scottish farming. The reform introduced decoupling of direct payments, i.e., replacement of production based subsidies by single farm payment (SFP) and compulsory modulation of funds from direct payments (Pillar 1) to measures in the Scottish Rural Development Plan (Pillar 2). The Scottish Executive has opted for full decoupling concerning the previously the existing coupled direct payments. In order to reduce the redistribution effects of the CAP reform, the Scottish Executive opted for SFP based on historic subsidy receipts from 2000 to 2002 rather than an area based flat rate payment system (EU-Commission 2003; SEERAD 2004a). Recognising the importance of beef cattle in Scottish uplands, the Executive has taken up the option to supplement the SFP with a beef national envelope, a new coupled Scottish Beef Calf Scheme (SEERAD 2004b). However, given the vulnerability of LFA agriculture to policy change, decoupling of direct payments is likely to have considerable influence on the direction of agriculture in LFAs regardless of any other measures. The introduction of the SFP may potentially lead to drastic extensification of land management in LFAs, particularly in uplands with lower quality land, because the new payment system does not provide incentives to maintain a certain amount of livestock (Moss et al. 2002, Burton et al. 2005).

While decoupling of direct payments has reduced the explicit production linkages, and one could argue thus also to some extent the sectoral linkages, of the CAP, it remains a sectorally focused policy. Moreover, both the SFP and SBCS have been uniformly implemented throughout Scotland and have no direct spatial or regional targeting. This raises the interesting question as to how the introduction of the SFP would affect regional di- mensions of the CAP and what potential changes to SFP and CAP in general could be derived to better address imbalances between different agricultural regions.

Against this background, the main objectives of the paper are to analyse the impacts of decoupling of direct payments on agriculture in LFAs in Scotland and to review the regional dimensions of a reformed CAP. The analysis differentiates between the impacts of decoupling of direct payments on different LFA and non-LFA farm types and applies a system-wide modelling framework, accounting for inter-sectoral linkage effects. Moreover the paper aims to assess feed-back effects of decoupling on the non-agricultural sector. For these purposes, we require a modelling approach that fully captures interactions between different sectors. CGE models are proving increasingly powerful and popular in this context. Such models build upon the inputoutput basic data but are capable of accommodating supply side constraints in a theory-consistent manner. This approach deals with the endogeneity of relative prices (and therefore competitiveness) and quantities as all markets equilibrate simultaneously.

The model distinguishes between six producing sectors, with five sub-sectors of agriculture and an aggregate non-agricultural sector. The sectoral disaggregation of the agricultural sector followed standard Scottish farm types identified in the Farm Accountancy Data Network (FADN) database. FADN was designed specifically to serve as an instrument evaluating the income of agricultural holdings and the impacts of the Common Agricultural Policy. The five standard farm types for Scotland identified in FADN were: specialist cereals, specialist dairy, mixed crops, sheep \& other grazing livestock, and cattle rearing \& fattening. Whilst the last two are classified as LFA farm types, the first three are classified as non-LFA farms.

In order to fulfill the objectives of this paper, four separate simulation runs were undertaken to implement the model and illustrate a range of conditions surrounding decoupling of direct payments. First, the initial database was replicated to ensure model consistency and accuracy while at the same time providing the base scenario. The second simu- 
Vol. 17 (2008): 3-17.

lation run applies decoupling of direct payments and describes a 50 percent reduction of coupled subsidies to LFA agriculture, based on the assumption that the amount of direct payments accounts for $50 \%$ of all support measures for farms in Scottish LFAs. The third and fourth simulation runs take into account varying production parameters for LFA farm types, i.e., constant elasticity transformation in production, to reflect bigger constraints for LFA farms to undertake necessary adjustments particularly in terms of limited options to switch from one farming enterprise to another.

The paper is structured as follows. Section 2 discusses sectoral and regional aspects of the CAP and provides a brief literature review on relevant aspects of quantitative CAP analysis. Section 3 highlights the modelling framework used for the analysis of decoupling. Section 4 discusses simulation results, with details of quantified impact of decoupling on LFA farms and identifying feed-back effects on the non-agricultural sector. Section 5 discusses some potential policy implications for the SRDP of the expected changes in land management. Finally, concluding remarks are provided in section 6 .

\section{The common agricultural policy: evolving from a sectoral to a regional policy?}

The Common Agricultural Policy (CAP) has been introduced more than forty years ago as one of the main sectoral policies in the European Union (EU). Since its introduction, the CAP has undergone a significant evolution and reform process driven by factors such as budgetary constraints and EU enlargement, WTO negotiations and environmental concerns (Swinnen 2003, Binfield et al., 2004). The Mc Sharry reform in 1992, the Agenda 2000 in 1999 and the Fischler reform in 2003 introduced major changes to the agricultural policy framework in the EU. For example, the Agenda 2000 reform introduced the second Pillar of the CAP by Rural Development Regulation 1257/1999 and the Fischler reform introduced the SFP which decoupled direct payment from production since 2005. In particular, the introduction of Pillar 2 added some regionalization and nationalisations to the CAP implementing a limited amount of scope for member states to design their own Rural Development Programmes (RDPs).

Buller (2003) concludes that recent policy developments point out a move away from common policies towards regional and national policies bringing a greater diversity of policy instruments. In this context, comparing the French and British approaches in their rural development programmes, Lowe et al. (2002) identified three new aspects in CAP development: subsidiarity, multifunctionality and territoriality; they conclude that the CAP will evolve into a broad framework within which Member States can apply an increasing range of policy measures targeted at territorial priorities. Specifically with respect to Pillar 2 of the CAP, Dwyer et al. (2002) identified noticeable differences in how countries and regions have designed their RDPs and differentiated between those who used the RDP as a tool to promote environmental land management and those for whom modernization of agriculture remains the main priority.

While recent developments point towards a stronger nationalization and regionalization of mainly Pillar 2 of the CAP within a broad EUwide framework, the CAP maintains its sectoral focus through market support measures and direct payments. This is confirmed by a recent EU-wide study which has analysed the territorial impacts of the CAP (Shucksmith et al., 2005), which concluded that the CAP does not support territorial cohesion objectives with higher levels of CAP expenditure per hectare of utilized agricultural area allocated more to prosperous regions. While rural development measures such as LFA payments and agri-environment payments may in some cases support territorial objectives and priorities, the overall regional and territorial impact of the CAP is dominated by Pillar 1 support. Dax (2006) stated that the geographical occurrence of Pillar 1 support is largely related to the distribution of farm types 


\section{AGRICULTURAL AND FOOD SCIENCE}

\section{Gelan, A. \& Schwarz, G. Impacts of decoupling on agriculture in Scottish less favoured areas}

and sizes across Europe. Regions characterized by larger farms, irrigated land use systems and complex cultivation and pasture systems are receiving higher levels of support. Moreover, the level of support seems to be correlated to the accessibility of regions, whereby more accessible European regions receive higher support levels (Dax, 2006). Despite the increasing nationalization of CAP measures, in particular in Pillar 2, the above discussion shows that the CAP remains essentially a sectoral policy with only limited targeting of regional objectives; thus spatial dimensions and implications of the CAP have not yet been taken sufficiently into account in the design of the CAP (Shucksmith et al., 2005, Dax, 2006, Thomson and Psaltopoulos, 2004).

The recent introduction of the SFP has decoupled direct payments from agricultural production, hence reduced the sectoral linkages of the CAP. On the other hand, in particular in cases where the SFP is based on historic payments, the introduction of the SFP did not explicitly implement mechanisms to better address regional implications of the CAP. This suggests that although the sectoral linkages of the CAP have been reduced, the introduction of the SFP does not improve regional dimensions and imbalances between different agricultural areas, e.g. between upland and lowland regions. This raises an interesting question as to how the introduction of the Single Farm Payment would affect regional dimensions and what potential changes to SFP and CAP could be derived to better address imbalances between different agricultural regions.

A large number of studies have been carried out to assess the potential implications of the introduction of the SFP for the agricultural sector in the EU and $\mathrm{UK}^{1}$. At EU level, for example, Britz et al. (2006) studied the effects of decoupling of land use using the Common Agricultural Policy Regionalised Impact (CAPRI) model. CAPRI covers all EU15 member states, disaggregated to some

$1 \quad$ Given the large number of modelling systems that have addressed the impact of CAP reforms, we focus in our review only on a few recent examples. Comprehensive overviews on the state of the art in the European modelling systems can be found, for example, in Heckelei et al. (2001), Arfini et al. (2005), and Antón (2006).
200 sub-national regions at the NUTS-II level, but focuses on the agricultural sector and does not captured feed-back effects between agriculture and the rest of the economy (Tongeren, 2004). Balkhausen and Banse (2006) analysed the effects of decoupling on land use and ruminant production in selected EU Member States using the partial equilibrium European Simulation Model (ESIM). Their results confirmed the dependency of the future ruminant production in the different member states on the applied decoupling approach predicting an increase in countries which have chosen partial decoupling and a decline in countries where payments are fully decoupled.

In the UK context, Moss et al. (2002) assessed the implications of decoupling for the beef, sheep, dairy, cereals and rapeseed sectors in the UK using the Food and Agricultural Policy Research Institute (FAPRI) modelling system. Similarly, Revell and Oglethorpe (2003) analysed the potential impact of decoupling on the livestock sector using a partial equilibrium model to examine aggregate effects as well as farm-level linear programming models to assess the impact on different livestock farm types. Both studies conclude that decoupling leads to a more extensive livestock production in the UK and estimated stronger reductions in livestock numbers in the UK compared to the rest of the EU, due to greater subsidy dependency of the UK cattle and sheep sectors. Specifically for Scotland, Allanson (2004) studied the distribution effects of the CAP reform on farm income inequalities in Scotland. However, such LP models do not allow intrinsically for any aggregate sector- and economy-wide adjustments in the model simulations and thus cannot capture economy-wide feedback effects into farm-level adjustment.

Most of the above examples covered the agricultural sector in reasonable detail, but they do not cover economic feed-back effects to the wider economy. Recent examples for studies considering both the agricultural sector in detail and economy-wide implications of the CAP reform include Gohin (2006) and Dixon and Matthews (2006). Gohin (2006) used a static multi-sector general equilibrium model of the EU15 economy to test the sensitivity of decoupling results with respect 
Vol. 17 (2008): 3-17.

to different modeling assumptions of Agenda 2000 direct payments. While the effects of decoupling are always negative for arable crop and beef production, he emphasized the impact of land market imperfections on the extent of production reductions in comparison between the different agricultural commodities. Dixon and Matthews (2006) analysed the impact of the CAP reform on the Irish agricultural sector and overall economy using a sectorally disaggregated Computable General Equilibrium (CGE) model. Their result show a significant change in the allocation of the resources within the agricultural sector, but economy wide effects of CAP reform are minimal, with a small positive impact on GDP. However, both studies do not take into account in the CAP analysis regional dimensions and constraints.

However, it is possible to integrate spatial dimensions of the CAP analysis in a CGE model by differentiating between upland and lowland farming or LFAs and non LFAs. In this paper we present an economy-wide modeling approach which differentiates between agriculture in LFAs and nonLFAs. Scottish LFAs are characterized by sheep and beef upland livestock systems and thus provide a suitable case study for the impact of the introduction of the SFP on uplands. The Scottish case study, presented in this paper, allows to explicitly analysing the regional implications of decoupling for upland agriculture and generates useful insights into regional dimensions of the CAP applicable for other Member States with similar natural and agronomic conditions.

\section{Impacts of decoupling on ag- riculture in LFA: a modelling framework}

The discussions in the preceding sections have highlighted background problems and related policy issues and provided some insights into conditions of production in LFA agriculture. This section brings these elements together in a system-wide modelling framework with a focus on the process of price determination through demand and supply interaction and the role of farm subsidy payments, which essentially is a wedge between producer prices and market prices. The primary focus of this analysis is to quantify the impact of CAP reform on LFA agriculture and the differential impact on these farm types is examined in a system-wide modelling framework accounting for inter-sectoral linkage effects. Gohin and Moshichini (2006) have undertaken a useful comparison of partial and general equilibrium approaches in evaluating the market and welfare impacts of agricultural policies in developed countries. They found that both modeling approaches lead to similar results, but welfare impacts may depend on model choice. However, if there is an interest in accounting for inter-industry feed-back effects then CGE modeling approach would become most relevant. In this study, we opted for a CGE modelling approach primarily to be able to capture interactions between agriculture and non-agricultural sectors. CGE models are proving increasingly powerful and popular in this context. Such models build upon the input-output basic data but are capable of accommodating supply side constraints in a theory-consistent manner. This approach deals with the endogeneity of relative prices (and therefore competitiveness) and quantities as all markets equilibrate simultaneously.

Gelan and Schwarz (2006) provide a detailed description of the formulation of the model, regarding its conceptual basis, theoretical framework as well as the accompanying system of equations and the baseline database or the social accounting matrix (SAM). The discussion here focuses on key elements of model formulation that are most relevant to this paper. Given that the primary motivation for this paper is to examine differential impacts of the policy reform on LFA agriculture, a suitable sectoral classification was established to account for this in implementing the model. Accordingly, the model distinguishes between six producing sectors, with five sub-sectors of agriculture and an aggregate non-agricultural sector. The sectoral 


\section{AGRICULTURAL AND FOOD SCIENCE}

\section{Gelan, A. \& Schwarz, G. Impacts of decoupling on agriculture in Scottish less favoured areas}

disaggregation of the agricultural sector followed the standard Scottish farm types identified in the FADN database. ${ }^{2}$ The five standard farm types for Scotland identified in FADN were: specialist cereals, specialist dairy, mixed crops, sheep \& other grazing livestock, and cattle rearing \& fattening (see Table A1.1 in Appendix 1). Whilst the last two are classified as LFA farm types, the first three are classified as non-LFA farms. The classification of sheep and other grazing livestock and cattle rearing and fattening as LFA farm types follows the farm type standardization applied by the Scottish Executive. With the exemption of lowland cattle farms, cattle and sheep farms are classified as LFA farms in the Farm Account Survey, which forms the basis of the Scottish FADN data. As the FADN database does not differentiate between upland and lowland farms and the large majority of cattle and sheep are produced on LFA farms (e.g. nearly $80 \%$ of the output of the sheep sector are produced by LFA farms (SEERAD, 2003)), the paper follows the assumption that sheep \& other grazing livestock and cattle rearing \& fattening farm types are classified as LFA farm types.

The aggregate non-agricultural sector produces a composite non-agricultural commodity, which means that there is a one-to-one activity-commodity correspondence for this sector in this model. However, each farm type produces a range of agricultural products, which are classified into ten major commodity groups: cereals, potatoes, other crops, beef, sheep, pigmeat, poultry, milk, other livestock products, and other output. These major groups are created from standard classifications in FADN database (see Table A1.2 in Appendix 1).

Graphic display of the production structure, activity-commodity links, and flows of marketed commodities is provided in Fig. $1 .^{3}$ Focusing on panel I of the diagram, starting from activity level $\left(\mathrm{QA}_{\mathrm{a}}\right)$ and following the arrows upwards,

2

For the ideas behind the creation of this database, see http://europa.eu.int/comm/agriculture/rica/ index_en.cfm

3 The description of this diagram in the subsequent paragraphs of this section heavily draws on section 4 of Gelan and Schwarz (2006), where further details of the structural equations for the model, with block by block illustration of institutional accounts are available. production is modelled as a nested multi-level structure allowing for variations in substitution parameters at different stages and hence bringing greater realism into the modelling framework. The first level of the nesting structure determines sectoral output $\left(\mathrm{QA}_{\mathrm{a}}\right)$ as aggregation of intermediate inputs $\left(\mathrm{QI}_{\mathrm{a}}\right)$ and value-added $\left(\mathrm{QVA}_{\mathrm{a}}\right)$ using a Leontief functional form which means that substitution between these inputs is not allowed at this level (subscript a denotes activity or sector). At the second level of the production nest, the value-added and intermediate composites are split into their components. On the one hand, the composite quantity of intermediate demand by each producing sector is disaggregated into demand for commodities from each farm type and the composite non-agricultural good. On the other hand, the value-added composite is decomposed into labour, land and capital with a CES (constant elasticity of substitution) functional form, which allows substitution between factors of production. Demand for factors of production is derived from the first order conditions of profit maximisation. This means that quantity demanded for each factor $\left(\mathrm{QF}_{\mathrm{a}}\right)$ is a decreasing function of the corresponding factor prices $\left(\mathrm{PF}_{\mathrm{a}}\right)$ and an increasing function of the volume of output $\left(\mathrm{QA}_{\mathrm{a}}\right)$.

Panel III displays flows of marketed commodities. The upper part shows a Constant Elasticity of Transformation (CET) function, allocating domestic commodity output $\left(\mathrm{QX}_{\mathrm{c}}\right)$ to different geographical destinations: domestic sales $\left(\mathrm{QD}_{\mathrm{c}}\right)$, exports to RUK $\left(\mathrm{QEK}_{\mathrm{c}}\right)$, and exports to rest of the world

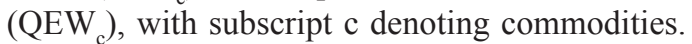
The lower part of the diagram shows determination of domestic demand for a commodity composite $\left(\mathrm{QQ}_{\mathrm{c}}\right)$ from a two-way aggregation. In Fig. 1, CET is defined as Constant Elasticity of Transformation and CES is defined as Constant Elasticity of Substitution. Subscript "a" denotes activities, five producing sectors listed in Table A2.1 below. In the context of inter-activity intermediate input flows $\left(\mathrm{QI}_{\mathrm{a}, \mathrm{a}}\right)$, "ap" means a reference or purchasing sector while "a" means the other or supplying sectors. Subscript "c" represents commodities. The ten commodity groups are listed in Table A2.2.

On the one hand, it is determined as a Leontief 
Vol. 17 (2008): 3-17.

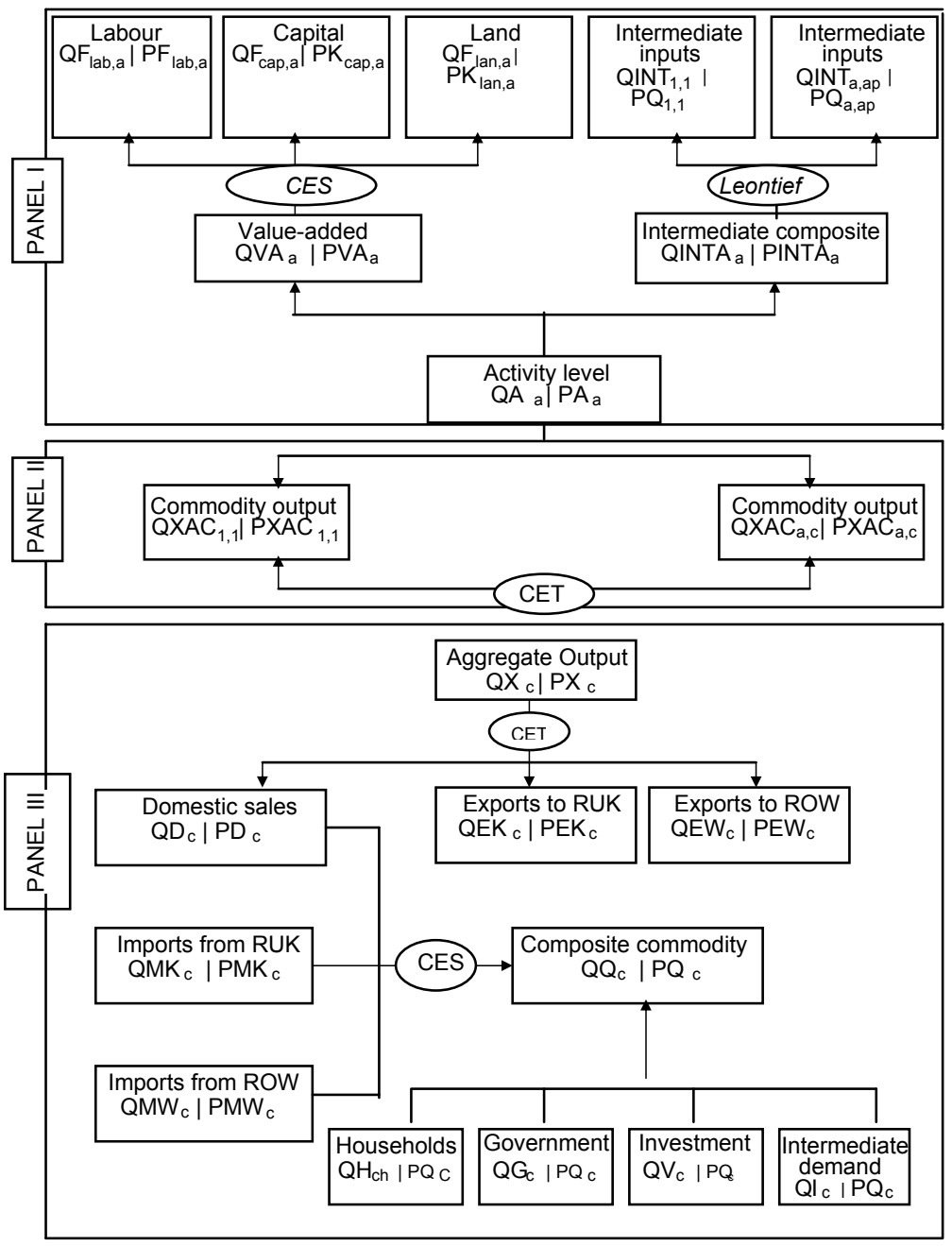

Figure 1. Structure of production and flow of marketed commodities. aggregation of demand by domestic institutions: producers (intermediate demand); rural households, urban households, and government (final consumption demand); and capital formation or investment demand. On the other hand, the Armington assumption is employed to disaggregate demand into commodities from different geographical origins using a Constant Elasticity of Substitution (CES) functional form. The Armington assumption implies that commodities from different geographical origins are treated as imperfect substitutes (Armington 1969).
At this juncture, it is important to illustrate how the introduction of decoupled direct payments enters the system and affects relationships between commodity demand and supply. Noting that farm subsidy payments are wedges between prices received by farmers and prices paid by buyers of farm output, the natural starting place is price changes in commodity markets, both local sales and export markets (RUK and ROW). This means the reduction of output related subsidy directly affects agricultural prices in domestic markets (PDc) and export markets (PEKc and PEWc) (See blocks in the 
second row of panel II). PDc is expected to rise and hence this causes substitution away from Scottish agricultural products (a decline in QDc) to imports from RUK and ROW (QMKc and QMWc). PEKc and PEWc denote the actual receipt by Scottish producers from exports sales in RUK and ROW markets. Employing a "small country assumption" whereby Scottish exporters sell at a given price in both export markets, the outcome of the reduction in output subsidy would be to reduce the local price of export goods, PEKc and PEWc and, noting direct relationship between supply price and quantity supplied, the amount farmers are willing to produce for export to external markets, i.e., QEKc and QEWc, would fall. Consequently, quantity of an agricultural output $(\mathrm{QXc})$ is expected to fall, as long as there is a reduction in direct output subsidy. However, the actual amount by which agricultural output declines from the baseline would depend on a range of parameters. These include the degree to which Scottish consumers would be sensitive to price changes and then switch away from domestic goods to imports (demand elasticity parameter in the CES function in panel II) and producers perception of the decoupled nature of the single farm payment and hence vary farm output in response to reductions in output based subsidy (output supply and export demand elasticity parameter in the CET function in panel II).

The preceding paragraph illustrates the impact of the policy shock on the level of aggregate output for a particular commodity output. However, given that each farm type produces a range of commodity output, the modelling framework needs to handle the further complications related to the translation of a decline in aggregate commodity output ( $\left.\mathrm{QX}_{\mathrm{c}}\right)$ into changes in an aggregate activity output $\left(\mathrm{QA}_{\mathrm{a}}\right)$. This is accomplished by introducing another variable QXAC $_{\mathrm{a}, \mathrm{c}}$, which represents the amount of commodity $\mathrm{c}$ produced by activity a or the amount of activity a in total production of commodity c (see Panel II). This transformation depends on the share parameter in the baseline data and the functional form employed to implement this conversion. The introduction of this panel in the modelling framework enables one to handle complexities in commodity-activity relationships by incorporating farm type or commodity specific supply constraints. More specifically, when output related direct subsidy payments are reduced, it may become more economical for farmers to switch away from farm outputs historically subsidised (e.g., sheep and beef) to those that have been producing without any or small amount of subsidy. However, the realisation of this shift in production would depend on the prevailing conditions of agriculture. Recalling the discussion in earlier sections regarding conditions of LFA agriculture, it becomes apparent that the LFA farms are likely to have limited options to undertake structural transformation from one line of farm activity to another.

The model was implemented with a database for the base year 2001. This database consists of a SAM for Scotland largely based on the 2001 Scottish Input-Output database but this is also supplemented by Scottish national income accounts published in various issues of Scottish Economic Statistics. These databases provide system-wide relationships between Scottish agriculture and the rest of the economy (including imports and exports). We have relied on FADN database to disaggregate the agriculture across farm types and commodity groups with the corresponding subsidy rates. This involved a data adjustment procedure whereby the consistent and comprehensive information for Scottish Agriculture remained a control figure but it was disaggregated into farm type categories and commodity groups given in FADN database. In the Scottish SAM, sectoral value-added constitutes the bulk of household income in each region. Households also receive transfer payments from the government and the rest of UK. Given that agriculture is mainly a rural activity and that agricultural income largely goes to rural households, it was essential to have separate accounts for rural households and urban households in formulating the model.

Finally, it is useful to bear in mind that the formulation of this model essentially followed a comparative static approach with no variation in the size of factor endowment in the economy during the simulation period. The parameter values for substitution elasticities for most CES and CET functions (displayed in Fig.1) were given as 1.5 all 
Vol. 17 (2008): 3-17.

sectors except for the factor substitution elasticity for the non-agricultural sector which is held at 2.5. At this stage of model formulation and development, we have focused on the "impact interval effect" or the "immediate effect" of the exogenous shock, decoupling of direct payments, on a range of economy-wide variables. Medium and longterm impacts of the policy shock through induced impacts, for instance, on changes in labour supply via migration or adjustments to capital stock via investment are left for future research (Harigan et al 1991).

\section{Simulation results}

The simulation experiments were confined to the introduction of the SFP, hence decoupling of direct payments, other aspects of the CAP reform such as the introduction of the SBCS, modulations of single farm payments, or progressive reductions in the amount paid, were not considered. Examination of Scottish subsidy data showed that pillar 1 direct payments which have been substituted by the SFP accounted for about 50 percent of the total amount of subsidies for agriculture during the base year, while the remaining proportion of the total subsidy amount was either not direct payment or not included in pillar 1 (such as the LFA Support Scheme), hence has not been included in the SFP. Thus, the policy shock, the introduction of the SFP, applied to the model was removing 50 percent of subsidies to farmers as "producers" and then transferring this amount to farmers as "households". The policy shock is allocated to the different commodities, depending on their share on the total amount of direct payments in the base year, and then transmitted to farm types through the different commodities they produce. The model distinguishes between rural households and urban households. This distinction is important because the policy reform essentially relocates funds from production subsidy to farming household income support. There is a government account in the model and it transfers subsidies from the production account to the household account.
This policy shock was applied to the model under three alternative scenarios.

Four separate simulation runs were undertaken to implement the model and illustrate a range of conditions surrounding decoupling of direct payments. First, the initial database was replicated to ensure model consistency and accuracy while at the same time providing the base scenario (henceforth S0), which provides a bench mark against which subsequent scenarios would be compared. In S1, the policy shock was applied to the model and results from this scenario were compared with the results from S0. In S2, two separate simulation runs were implemented successively reducing parameters specific to production possibility constraints in LFA farms types.

\section{Scenario I: Impacts of the introduction of the single farm payment}

Table 1 displays impacts of the introduction of the SFP by commodity groups. The largest impact happened to sheep and related products, with a decline in output of this commodity by 47.1 percent, which was very close to the assumed rate of decline in

Table .1 Impacts of the introduction of the SFP by commodity groups.

\begin{tabular}{lc}
\hline Commodity categories & $\begin{array}{l}\text { \% change } \\
\text { from base year }\end{array}$ \\
\hline Cereals & -21.00 \\
Potatoes & 0.35 \\
Other crops & 0.34 \\
Beef & -38.58 \\
Sheep & -47.14 \\
Pig meat & 0.41 \\
Poultry meat and egg & 0.44 \\
Milk and milk products & 0.33 \\
Other livestock and products & -1.79 \\
Other miscellaneous activities & 0.66 \\
Non-agricultural commodities & 0.29 \\
\hline
\end{tabular}


direct payments. Other agricultural commodity groups with substantial declines were cereal and cattle, with 38.6 percent and 21.0 percent falls respectively. Similarly, the other livestock and related products are likely to be adversely affected by the policy reform but its rate of output contraction is relatively small.

Simulation results in S1 confirm that the impact of the SFP on commodity output closely follows the pattern of output subsidy rates in Scottish agriculture. A substantial proportion of output related subsidy payments have traditionally been headage payments for sheep and cattle or arable area payments for cereals. As we expect, when subsidy payments are decoupled from production then these commodity outputs experience larger declines than other agricultural commodity groups.

Accordingly, other agricultural products that have not historically been directly subsidised experience small expansions. The results displayed in Table 1 for these groups of agricultural goods may look numerically small but the direction of change has important implications. The fact that historically subsidised agricultural outputs contract but those that have not traditionally been subsidised show a slight expansion suggests that the SFP may induce some structural changes in Scottish agriculture. The relatively small but positive numerical changes may be influenced by the modelling framework employed to simulate the policy impact. More specifically, the results obtained here reflect changes in relocation of resources that may lead to output expansion even in the short-run, e.g., agricultural labour force but capital stock still remaining at the base year level. However, a dynamic modelling framework would allow for variations in investment and hence capital stock and make it possible for more realistic simulation results regarding structural change in Scottish agriculture. Such improvements in the modelling framework are left for future research.

The positive feed-back effect of the policy shock was not limited to the traditionally unsubsidised agricultural products but also to the rest of the economy, represented in Table 1 by the "nonagricultural commodities". This suggests that the introduction of the SFP may have a positive feed- back effect on the rest of the economy, although the magnitude of the positive inter-industry linkage effects was relatively small because only short-run impacts are considered in these simulation experiments.

Fig. 2 presents the impact of the introduction of the SFP on different farm types. The impact of the policy shock on agricultural output by commodity grouping (displayed in Table 1) does not necessarily reflect impacts on different farm types. The impact of the SFP on different farming sectors, among other things, depends on the commodity composition of farm output. The larger the share of historically subsidised output categories (e.g. sheep, cattle, cereals, etc) in the total output of a particular farm type, the greater the impact of decoupling on that particular farm type. Accordingly, the simulation experiment showed that cattle and sheep farm types would expect to encounter the largest contraction in their farming activities, with 31 percent and 28.7 percent respectively. In each case, the proportionate declines were less than the corresponding falls in principal commodity groups produced by these farm types (i.e., finished cattle and sheep) because of diversification effect. This means that since farm types under the "cattle" category also engage in other farming activities like cropping and other livestock, the overall impact on this farm types was given as a weighted average of

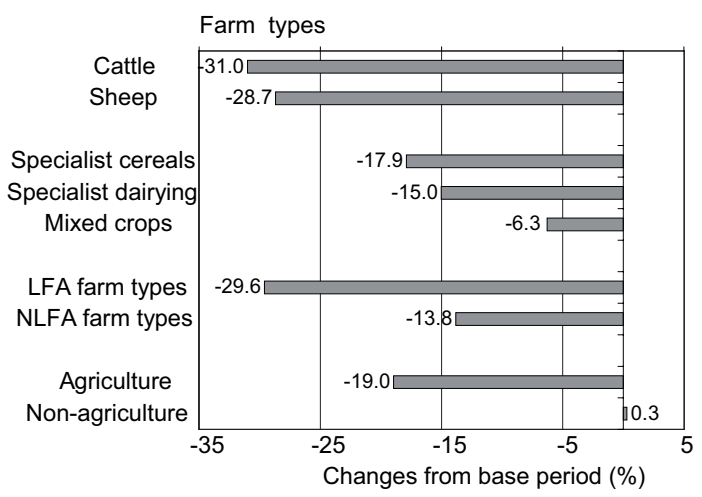

Figure 2. Impacts of the introduction of the SFP on output by activity groups. 
Vol. 17 (2008): 3-17.

the policy impact across these commodity groups. Farms whose main activities are cereals, dairy and mixed cropping experience output declines of 18 percent, 15 percent and 6.3 percent respectively.

The standard farm types were also regrouped into LFA (cattle and sheep) and non-LFA (cereals, dairy and mixed cropping) to show the differential impact of the policy shock on these major farm types (Fig. 2). In our modelling framework, LFA farms expected to encounter output contraction by about 29.6 percent, which was more than twice the average proportionate decline for non-LFA farms. This revealed the central issue regarding possible differential impacts of CAP reform on different agricultural products and hence farm types. In this simulation scenario, the results reflect how farmers may respond to the policy shift away from output linked subsidy, assuming uniform farmer response in all farm types. As noted above, the simulation experiments showed higher adverse impacts of the policy reform on LFA farms even when we do not introduce farm specific parameters.

Finally, the overall impact of the introduction of the SFP on agriculture is expected to be a contraction by 19 percent. The positive inter-sectoral linkage effect on the aggregate non-agricultural sector remains at 0.3 percent increase as in Table 1 because there is no activity-commodity difference for this sector in this modelling framework.

\section{Scenario 2: Sensitivity of LFAs farm types to the policy shock}

The simulation results reported in the previous sections were obtained disregarding differential impacts of the decoupling policy across different farm types. Given that a similar modelling structure and parameter values were used in undertaking the simulations runs, the differential impacts reported in the $\mathrm{S} 1$ reflect differences in rates of historical farm subsidy payments rather than any farm specific behavioural response.

However, as outlined in earlier sections, the policy shock may affect farms in LFAs more than other farm types due to production constraints specific to the these farms. In other words, output related subsidy might have encouraged farmers in LFAs to stay in farming. If subsidy is decoupled from output then LFA farms may no more be viable operating units because they are likely to be more constrained to undertake necessary adjustments

In this modelling framework, such differential impact was implemented by varying production parameters, i.e., constant elasticity of transformation in production. This encapsulates, among other things, conditions of production adjustments at different time scales (see variable QXACa,c in panel II of Fig. 1). A relatively low value of elasticity of substitution would mean that given its existing activities represented by the baseline share parameter, farm type "a" has a limited option to respond to the policy shock by switching production between different commodities denoted by "c".

The simulation experiments for scenarios S0 and $\mathrm{S} 1$ were undertaken with $\sigma_{\mathrm{ac}}=1.5$ for all commodity groups. In scenarios S2 and S3, the value of this parameter for cattle and sheep products (i.e., mainly LFA type farms) was reduced to 1.3 and 1.1 respectively. Table 2 displays simulation results obtained with these parameter variations, with the first column representing S1 results which were reproduced here for convenience in comparing results from all scenarios.

There are two distinct patterns of changes in output by commodity and activity groups. Cattle and sheep, i.e., commodity groups whose production substitution elasticity parameter exogenously reduced, experience further contractions in output as expected. Accordingly, with the parameter values of 1.5, 1.3 and 1.1; sheep and related output contracted by 47.1 percent, 50.4 percent and 53.6 percent while finished cattle output fell by 38.6 percent, 39.8 percent and 41.2 percent respectively. Since these farm outputs constitute a large proportion of LFA farm types, the level of activity change in LFA farm types declines by 29.6 percent, 31.2 percent and 32.9 percent respectively, which shows an inverse relationship with changes in the variations of the parameter values. Hall et al (2002, p. 5) employed a highly disaggregated farm level model and found out that farm business profit would be maximised with reduction in stock numbers which 
Gelan, A. \& Schwarz, G. Impacts of decoupling on agriculture in Scottish less favoured areas

Table 2. Impacts of the introduction of the SFP on output by commodity groups and activity groups with variations in production parameters.

\begin{tabular}{lrrr}
\hline Commodity-activity output $\backslash$ Production elasticity parameter & 1.5 & 1.3 & \multicolumn{1}{c}{1.1} \\
\hline Commodities: & & & \\
Cereals & -20.999 & -20.994 & -20.988 \\
Potatoes & 0.354 & 0.361 & 0.367 \\
Other crops & 0.339 & 0.346 & 0.352 \\
Beef & -38.581 & -39.788 & -41.173 \\
Sheep & -47.137 & -50.449 & -53.632 \\
Pig meat & 0.407 & 0.414 & 0.422 \\
Poultry meat and egg & 0.439 & 0.447 & 0.455 \\
Milk and milk products & 0.327 & 0.332 & 0.337 \\
Other livestock \& products & -1.795 & -1.788 & -1.781 \\
Other miscellaneous activities & 0.664 & 0.667 & 0.669 \\
Non-agricultural commodities & 0.295 & 0.300 & 0.305 \\
Activities: & & & \\
Specialist cereals & -17.895 & -16.705 & -15.541 \\
Specialist dairying & -15.023 & -15.574 & -16.238 \\
Sheep and other grazing livestock & -28.696 & -30.641 & -32.631 \\
Cattle rearing and fattening & -31.007 & -32.137 & -33.403 \\
Mixed crops & -6.286 & -5.457 & -4.253 \\
LFA farm type & -29.607 & -31.230 & -32.935 \\
NLFA farm types & -13.824 & -13.500 & -13.143 \\
Agricultural activity & -18.961 & -19.271 & -19.585 \\
Non-agricultural activity & 0.295 & 0.300 & 0.305 \\
\hline
\end{tabular}

ranged between $50 \%$ and $75 \%$ depending on farm sizes. This indicates that the farm level model and our economy-wide model give similar effects decoupling on farm outputs both in the direction and percentage terms.

The other pattern one could observe from Table 2 relates to changes in commodity outputs produced predominantly by non-LFA farm types. Although the substitution parameter corresponding to these groups of commodities and activities was held at the base scenario level, their output levels increase with the variations in the substitution parameters for principal LFA outputs. Accordingly, as the parameter values for LFA activities fall successively, then the negative effects of the policy shock on non-LFA commodity outputs either becomes smaller and smaller (e.g. cereals, other livestock $\&$ related products) or the positive policy effect becomes larger and larger (e.g. potatoes, other crops, milk, etc.). This suggests that the contraction in LFA type farms may have some positive feed-back effects on non-LFA farms. Such feed-back effects emanate from resource release from LFAs and their relocations to non-LFAs; although this is related to mobile factors (mainly labour) between different farms. Similarly, demand side substitution effects would mean contractions in LFA output may cause increase in the prices of these items in product markets and hence buyers may choose to purchase non-LFA farm outputs. As noted earlier, the significance of these inter-sectoral feed-back effects lie not so much in the absolute 
Vol. 17 (2008): 3-17.

magnitude of the changes but in the direction of the variations. It is expected that future improvements in the modelling structure with introduction of investment dynamics would add greater degree of realism to the outcomes.

Given that the relatively large contractions in LFA farms and some non-LFA farms but only small increases in other non-LFA farms, the overall effect on Scottish agriculture remains a contraction in all scenarios. On the other hand, the non-agricultural sector is expected to experience some positive feed-back effect under all scenarios.

\section{Discussion and conclusion}

The purpose of this paper was to quantify differential impacts of decoupling single farm payments on LFA and non-LFA farm types in Scotland. The model was implemented using Scottish data, which was compiled in a SAM format as well as additional data related to such variables as factors of production and exogenous elasticity parameters. The model was applied with a range of simulation runs which were conducted with a removal of 50 percent of the total Scottish agricultural subsidies to different farm types, an amount estimated to be subjected to decoupling, and transferring the same amount to households as income support. This policy shock was applied to the model under two separate simulation scenarios. The first scenario assumes that different farm types face similar constraints in adjusting to the policy shock while the second scenario relaxes this assumption and imposes an assumption that LFA farms have limited options in adjusting to the policy shock. This was implemented using a relatively lower substitution parameter for LFA farms than non-LFA farms.

The results of the simulations show that the introduction of the SFP could lead to significant reductions in agricultural activities in Scottish LFAs with a reduction of agricultural output of LFA farms of 30 percent or 33 percent, when specific production constraints of LFA farming are explicitly considered in the simulations. This confirms the differential regional impacts of the SFP on LFA and non-LFA farms, given the adverse impact on LFA farms is more than double the corresponding changes in non-LFA farm outputs which emphasises the strong dependence of agricultural activities in Scottish LFAs on subsidies. However, the economic implications of the SFP on LFA farms have knockon effects for the environment in uplands due to changes in land management and are linked with social issues in the upland farming sector which need to be considered in the discussion of territorial policy implications.

For the interpretation of the results of this study it is important to note that we followed the assumption that farmers perceive the SFP as fully decoupled from production and respond accordingly. Given that the SFP is still coupled to agricultural land, it would not be unreasonable to assume that farmers include, at least to a certain extent, the SFP in their business decision implying some production incentives through the SFP. Of course, this would lead to a smaller decline in agricultural activities in LFAs. Moss et al. (2002), for example, analysed decoupling of direct payments in the UK under different assumptions regarding farmers' response to decoupling and simulated different proportions of the direct payments as decoupled. Their results also indicate a significant reduction in upland livestock systems with a decline in suckler cows from 6 percent to 19 percent depending on the extent of decoupling. However, as the main objective of the simulations in this study is to identify the differential impact of the SFP on LFA (upland) and non-LFA (lowland) farm types, and because of the lack of reliable information on farmers' response to the SFP, we assume that farmers perceive the SFP as fully decoupled from production. As Gohin (2006) notes, further investigations of the modeling assumptions concerning the SFP are required.

In scenario 1, the impact of CAP reform on commodity output closely followed the pattern of output subsidy rates. A substantial proportion of output related subsidy payments were traditionally headage payments for sheep and cattle. As we expect, when subsidy payments were decoupled from production then those commodity outputs that have significantly been subsidised experienced larger declines than other agricultural commodity groups. 


\section{AGRICULTURAL AND FOOD SCIENCE}

\section{Gelan, A. \& Schwarz, G. Impacts of decoupling on agriculture in Scottish less favoured areas}

Since these commodity groups constitute a large proportion of LFA farm outputs, these farm types have shown larger activity declines than non-LFA farm types. On the contrary, commodities that were not traditionally subsidised showed a small increase from the base period. Similarly, aggregate output of the non-agricultural sector has experienced a small increase. The positive feed-back effects are largely explained by interactions in factor markets whereby resources released from farming sectors would be relocated and utilised in the other sectors.

The motivation behind scenario 2 was to capture a limited capability of LFA farmers to adjust to decoupling due to natural constraints. This is implemented by reducing the size of commodity production substitution parameters for LFA farms. When this assumption was imposed, LFA farms showed further activity declines; the rate of contraction for non-LFA farms has become smaller than with the previous experiment; and the positive feed-back effect on the aggregate non-agricultural sector increased. The results confirm the often cited assumption (Cook 2004, Moss et al. 2002, Matthews and Schwarz 2003, and Burton et al. 2005) that without specific livestock payments cattle and sheep systems in LFAs are in many cases not viable and livestock numbers would experience a strong decline. Given the production condition which predominantly favour rough grazing, but virtually nothing else, the upland farmer may find it impossible to diversify from the existing farm activity into another.

The simulation results suggested the risk that, without specific support to maintain farms in LFAs, the implementation of the SFP leads to land use extensification at larger scale and a reduction of LFA farms causing negative impacts on public good provision and harmful effects on certain rural communities. In a policy context, this further suggest that the introduction of a nation-wide uniformly implemented SFP does not improve territorial implications of the CAP and does thus not address regional imbalances between different agricultural areas. It follows that such differential impacts of the SFP across different farm types and areas need to be taken into account by forthcoming rural policy changes such as a new SRDP. Following from the policy discussion in the previous section, an important role of the SRDP can be derived as not only providing additional income transfer, e.g. through the LFASS, but also facilitating structural adjustment and diversification outside food production to create diversified and viable businesses and maintain farm households in rural communities. In that respect, axis 3 of the new RDR provides some relevant key actions supporting diversification of farms into other rural activities and broadening the scope of the SRDP.

However, designation of LFA areas is applied at a rather broad level and does not necessarily guarantee that socio-economic and natural conditions at farm-level are considered. The key point is that there is a need to consider spatially differential impacts in further adjustments to policy reforms taking into account local circumstances. It becomes essential to increase funding for the SRDP to provide meaningful support, coordinating agricultural policy with rural and regional development policies.

\section{References}

Allanson, P.2004. CAP Reform and the Distribution of Agricultural Support in Scotland. WorkingPaper No. 147. Dundee, Department of Economic Studies, University of Dundee.

Antón, J. 2006. Modelling Production Response to "More Decoupled" Payments. Journal of International Agricultural Trade and Development 2: 109-126.

Arfini, F. (ed.) 2005 Modelling Agricultural Policies: State of the Art and New Challenges. Proceedings of the 89th European Seminar of the European Association of Agricultural Economists. MUP, University of Parma.

Armington, P. S. 1969. The Geographic Pattern of Trade and the Effects of Price Changes, IMF Staff Papers 16: 176-199.

Balkhausen, O. and Banse, M. 2006 Effects of decoupling on land use and production in individual EU Member States - a Partial Equilibrium Analysis. Paper presented at the $93^{\text {rd }}$ seminar of the EAAE "Impacts of Decoupling and Cross-Compliance on Agriculture in an enlarged EU", Prague 22 - 23 September 2006.

Binfield, J, Donnellan, T., Hanrahan, K., Hart, C. and Westhoff, P. (2004) CAP Reform and the WTO: Potential Impacts on EU Agriculture. Paper presented at the American Agricultural Economics Association Annual Meeting, Denver, Colorado, July 1-4, 2004.

Britz W., Heckelei T., Perez I. 2006 Effects of Decoupling on land use: an EU wide, regionally differentiated Anal- 
Vol. 17 (2008): 3-17.

ysis', Agrarwirtschaft, Jahrgang 55, Heft 5/6, ISSN: 0002-1121, pp. 215-226

Buller, H. 2003. Future Policies for Rural Europe - 2006 and beyond. Paper presented at the Land Use Policy Group conference, Brussels, March 2003.

Burton, R.; Schwarz, G.; Fischer, H. 2005. Changes in farm labour structures on family farms and implications for the Rural Development Plan for Scotland. Journal Economie Rurale 289-290: 106-129

Cook, P. 2004. The impact of the CAP Mid-Term Review proposals on the Highlands of Scotland. Paper presented at the seminar: The impact of decoupled payments on High Nature Value Farming Systems, organised by The European Forum on Nature Conservation \& Pastoralism (EFNCP), on 21 January 2004. Available on the internet: http://www.efncp.org/semirep/210104/abstracts/vcook.pdf

Dax, Thomas 2006. The Territorial Dimension of CAP and Spatial Cohesion. La dimension territoriale de la PAC et sa cohésion dans l'espace. Die regionale Dimension der GAP und die räumliche Kohäsion. EuroChoices 5 (2): 12-19.

Dixon, J. and Matthews, A. 2006. Impact of the 2003 Mid Term Review of the Common Agricultural Policy, Economic and Social Research Institute Quarterly Economic Commentary Spring: 36-52.

Dwyer, J. 2005. The new Rural Development Regulation 2007-2013. Paper presented at the Outlook 2005 conference organized by Agra-Europe. London, 1-2 March.

EU-Commission 2003. EU Fundamentally Reforms its Farm Policy to Accomplish Sustainable Farming in Europe. http://europa.eu.int/rapid/start/cgi/guesten. $\mathrm{ksh}$ ?p_action.gettxt=gt\&doc $=|\mathrm{P} / 03 / 898| 0 \mid \mathrm{RAPID} \& \mathrm{Ig}=$ EN\&display

Gelan, A. and Schwarz, G. 2006. A Policy Impact Evaluation Model for Scotland: Decoupling Single Farm Payments. Aberdeen Discussion Paper Series ISSN 1743-9965.

Gohin, A. 2006 Assessing CAP Reform: Sensitivity of Modelling Decoupled Policies. Journal of Agricultural Economics, 57, 3, 415-440.

Gohin, A. and Moschini, G. 2006 Evaluating the Market and Welfare Impacts of Agricultural Policies in Developed Countries: Comparison of Partial and General Equilibrium Measures, Review of Agricultural Economics, 28(2): 195-211.

Hall, W.R; K. A. Phillips; S.A. Ford; J. Rockliffe; D Woodcock; M Topliff 2002 Assessment of the Potential Impact on Beef and Sheep Farming of Decoupling CAP Aid Payments from Production. A report prepared by ADAS limited for Beef and Sheep Division of DEFRA. http://statistics.defra.gov.uk/esg/reports/decoupling/Adas.pdf
Harrigan, F., McGregor, P., Swales, K. J., Dourmashkin, N., Perman, R., Yin, Y. P. 1991. AMOS: a Macro-Micro Model for Scotland, Economic Modelling, October: 424-479.

Heckelei, T., Britz, W. 2001. Concept and explorative application of an EU-wide regional agricultural sector model (CAPRI-Projekt). In: Heckelei, T., Witzke, H.P., Henrichsmeyer, W. (Eds.). Agricultural Sector Modelling and Policy Information Systems: pp. 281-290.

Lowe, P., Buller, H. and Ward, N. 2002. Setting the Next Agenda? British and French Approaches to the Second Pillar of the CAP. Journal of Rural Studies, 18, 1-17.

Matthews K., Schwarz G. 2003. CAP Reform: What will it mean for the Uplands of Scotland? Report of a workshop on CAP reform hosted by the Macaulay Institute at Hartwood Farm.

Moss, J.E., McErlean, S.A., Patton, M., Kostov, P., Westhoff, P. and Binfield, J. 2002. Analysis of the Impact of Decoupling on Agriculture in the UK. NI-FAPRI Project: Agri-Food Policy Analysis Report No 7.

Revell, B, Oglethorpe, D. 2003. Decoupling and UK Agriculture: A Whole Farm Approach. Report commissioned by DEFRA.

SEERAD (Scottish Executive Environment and Rural Affairs Department) 2003. Economic Report on Scottish Agriculture 2003 Edition. Published by the Governmental Statistical Service.

SEERAD 2004a. Common Agricultural Policy. http://www. scotland.gov.uk/pages/news/2004/02/SEEL791.aspx

SEERAD 2004b. The Scottish Beef Calf Scheme (SBCS). http://www.scotland.gov.uk/library5/rural/sbcs.pdf

SEERAD 2007. Scottish Rural Development Plan 2007-2013. Cited: 04 January 2007.

http://www.scotland.gov.uk/Topics/Rural.

Shucksmith, M., Thomson, K. and Roberts, D. (eds) 2005. CAP and the regions: the Territorial Impact of the Common Agricultural Policy. CAB international.

Swinnen, J. 2003. The EU Budget, Enlargement and Reform of the CAP and the Structural funds, paper to LUPG conference on future Policies for Rural Europe 2006 and Beyond, Brussels, March 2003.

Terluin, I. J., Godeschalk, F. E., von Meyer, H., Post, J. H, Strijkers, D. 1995. Agricultural Incomes in Less Favoured Areas of the EC: A Regional Approach. Journal of Rural Studies, 11 (2), pp 217-228.

Thomson, K. J., Psaltopoulos, D. 2004. Integrated rural development policy in the EU: A term too far? Eurochoices 3: 40-45.

Tongeren, F. 2004. Brief review of the CAPRI modelling system. Prepared for the final project meeting of the CAP-STRAT project (QLTR-2000-00394), Louvain-la Neuve, 20 February 2004. 